\title{
Yapıda HVAC Sistem Seçimi
}

\author{
Uğur ÖZCAN \\ Fatih Sultan Mehmet Vakıf Üniversitesi, Mimarlık ve Tasarım Fakültesi , Mimarlık Bölümü, İstanbul, Türkiye \\ (ORCID: https://orcid.org/0000-0003-0002-4478)
}

(Alınış / Received: 30.11.2018, Kabul / Accepted: 03.04.2019, Online Yayınlanma / Published Online: 26.04.2019)

\author{
Anahtar Kelimeler \\ Mimari tasarım, \\ İklimsel konfor, \\ Isitma, \\ Soğutma, \\ Havalandırma
}

\begin{abstract}
Özet: İnsanların hayatlarını sürdürdükleri yapıların; gelişen teknoloji ve nüfus artışı ile orantılı biçimde arttığı görülmektedir. Ülkemiz üzerinden yapılan araştırmalara göre özellikle inşaat sektöründeki üretim yüksek bir seviyeye ulaşmıştır. Bu üretilen yapıların üzerinden; "kullanıcı konforu bu oranda artış sağlamakta mıdır?", "bu artışa paralel olarak solunan hava ne kadar kaliteli ve niteliklidir?" veya "hava kalitesi ve kullanıcı sağlığı için neler yapılmalı?" gibi sorular akla gelmektedir. Bu bağlamda kullanıcı konforu ve sağlığı için çözüm önerisi olarak HVAC sistemlerin doğru seçim ve kullanımından bahsedilmiştir. HVAC sistemlerin yapı tasarımı tamamlandıktan sonra alternatifler olarak değil, daha yapıya ait eskiz çalışmaları hazırlandığı sırada düşünülmesine ve çevresel faktörlerin doğru analiz edilmesinin önemine vurgu yapılmıştır. Bu sistemlerin seçimi ve tasarımı sırasında, hedefler ve öncelikler belirlendikten sonra, tasarımcılar için bir ön görü kılavuzu oluşturmak amaçlanmıştır.
\end{abstract}

\section{HVAC System Selection on Structure}

\section{Keywords}

Architectural design, Climatic comfort,

Heating,

Cooling,

Ventilation

\begin{abstract}
It is observed that the structures are increasing in proportion with developing technology and population growth. According to research conducted over our country, especially in the construction sector production has reached a high level. "Does user comfort increase this rate?", "how high quality and quality is the air breathed in parallel with this increase?" or "what should be done for air quality and user health?" as such, questions come to mind. In this context, the correct selection and use of HVAC systems is mentioned as a solution proposal for user comfort and health. After the construction design of HVAC systems is completed, it is emphasized that not as alternatives, but as sketches of more buildings are prepared and the importance of accurate analysis of environmental factors is emphasized. During the selection and design of these systems, after the objectives and priorities have been determined, it is aimed to create a pre-view Guide for designers.
\end{abstract}

\section{Giriş}

Tasarımclar ve kullanıcılar genellikle en iyi, en güzel ve en ekonomik olana yönelmeyi kendilerine amaç edinirler. Bu amaçtan hareketle, yaşam mekânlarında bir dizi seçim kriterini göz önüne alarak çeşitli tercihlerde bulunabilirler. Mekâna ait istenen iklimsel konfor kriterleri, kullanılması planlanan iklimlendirme sisteminin seçiminde belirleyici olmaktadır.

Günümüzde yaşanan çevrenin kirliliğinden sık sık bahsedilir duruma gelinmiştir. Nüfus yoğunluğu, gelişen teknoloji, bu teknolojinin ihtiyaç fazlası üretimi ve kullanımı, dolayısı ile tüm bu durumun oluşturduğu çevresel kirlilikten ve farklı birçok kirlilik kaynaklarından söz edilmesi mümkündür. Özellikle nüfusun yoğun olduğu bölgelerde, çevre kirliliği yoğun olabileceğinden, kullanıcıların kapalı yaşam alanlarında filtresiz doğal havalandırma ile ne kadar sağlıklı ortamlar oluşturabilecekleri tartışılır durumdadır. $\mathrm{Bu}$ noktada, özellikle yoğun nüfuslu kentlerde yaşayan insanların, kapalı mekânlarda kirlilikten uzak, sağlıklı bir iç hava kalitesi sağlanmasına olanak veren HVAC (Heating, Ventilating and Air Conditioning) sistemler çözüm alternatifleri sunmaktadır.

HVAC (Isıtma, Havalandırma ve İklimlendirme) sistemler; bünyesinde farklı çalışma sistemlerine ve 
teknolojilere sahip, alternatif çözümleri birlikte veya ayrı ayrı sunabilen kapsamlı teknolojik yapılardır. Uygulama yapılacak yapıya sistem seçimi yapılırken, gerekli veriler titizlikle toplanmalı, öncelikler ve ihtiyaçlar belirlenmeli, sistem tercihi ve tasarımı bilinçli yapılmalıdır. Şekil 1'de sistem seçimi ve tasarımı için bir dizi gerekli veri başlıkları ve ilişkili durumları görülmektedir. Özellikle seçilecek olan sistemin, en az 15 yıl kullanılacağı ön görülmeli, ekonomik olup olmadığı, enerji tüketimi, sistemin sahip olduğu yetenekler ve bu noktada seçim ölçütlerindeki beklentileri ne düzeyde karşılayabileceği irdelenmelidir.

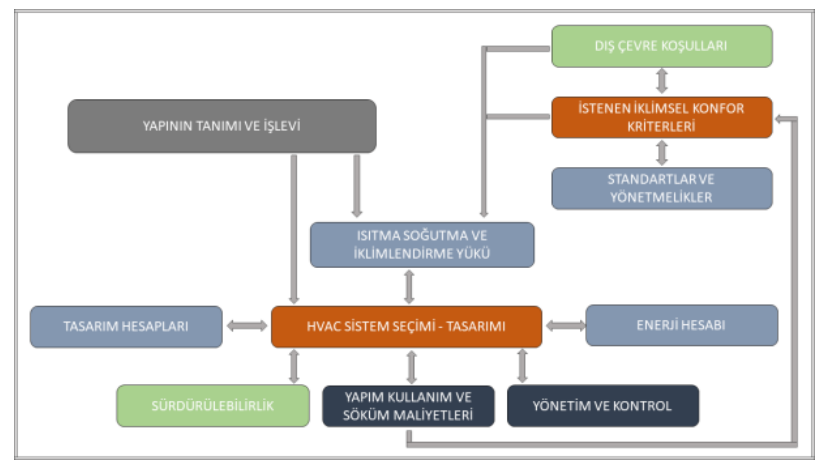

Şekil 1. Sistem Tasarımı İçin Gerekli Veriler

HVAC sistemlerin "ne için ?" ve "kim için ?" yapılacağl soruları, sistem tasarımı için çok önemlidir. Bu sistemler ısıl konfor ve iç hava kalitesinde çözüm olarak sunulmakta, dolayısı ile yapıda konfor arayışının merkez yapıtaşını oluşturmaktadır. Kullanıcıların fizyolojik özelliklerinin bilinmesi, iklimsel konfor kriterlerinin belirlenmesinde ve yük hesaplarının yapılmasında önemli bir role sahiptir. İklimsel konfor, iki temel değişken parametre ye bağlı olarak şekillenmektedir. Bunlar, çevresel değişkenler ve kullanıcılara ait kişisel değişkenlerdir. Şekil 2 ve Șekil 3'de insan vücudu ve çevresinin isıl etkileșim modelleri görülmektedir.

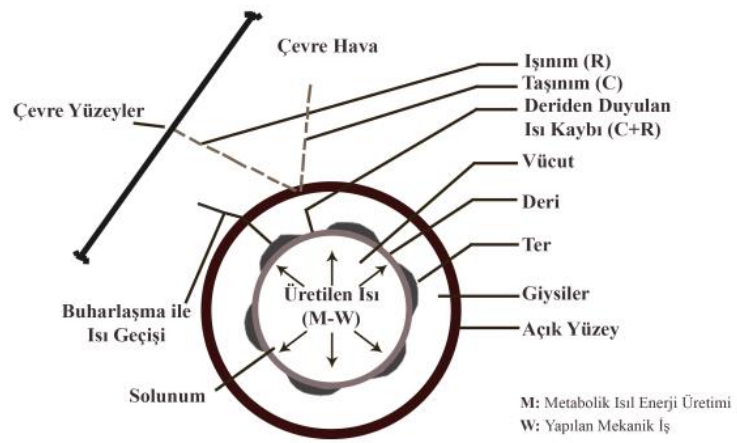

Şekil 2. İnsan Vücudu ve Çevresinin Isıl Etkileşim Modelleri

Çevresel değişkenler olarak, ortamın hava sıcaklığı, bağıl nemi, hava hareket hızı, iç ortamı çevreleyen yüzey sıcaklıkları sayılabilir. Kullanıcıya ait kișisel değişkenler olarak ise, bireyin aktivite düzeyi ve konumu, bireyin giyinme düzeyi, yaşı ve sağlı durumu şeklinde siralanabilir. Söz konusu parametreler, kullanıcıların bulundukları ortamda iklimsel konforun varlığını ve kullanıcılar tarafından algllanma düzeyi seviyesini belirlemektedir. Kullanıcı, bu parametreler doğrultusunda ısıl konfor ve iç hava kalitesi bakımından stabil bir ortamda bulunmalı, ortama ait konfor düzeyi denetlenmeli ve kontrol edilmelidir.

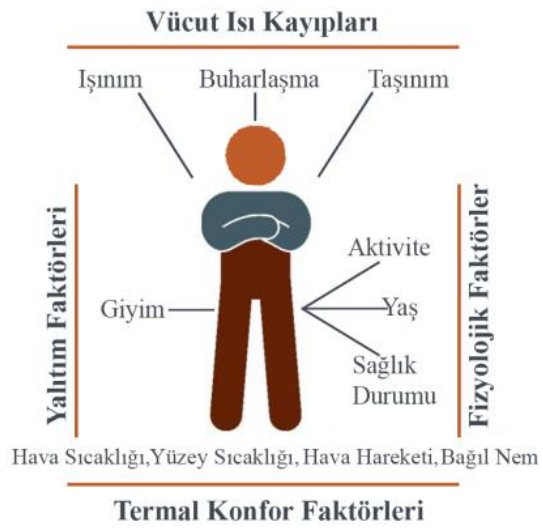

Şekil 3. İnsan Vücudu ve Çevresinin Isıl Etkileşim Modelleri

\section{HVAC Sistemler}

HVAC sistemler yapının ısıtma, soğutma, havalandırma, nem alma veya kurutma ihtiyaçlarının tümünü veya birkaçını sağlayan teknolojik ekipmanları, bu ekipmanların oluşturduğu sistemleri ve yapıya hizmet veren bu sistemlere destek sağlayan dağıtım ve borulama ağları ile terminal noktalarıdır. Yapı söz konusu HVAC sistemin bir veya birkaç farklı kombinasyonunu barındırabileceği gibi bu sistemler birbirlerine de destek ve servis sağlıyor olabilir. [1].

İklimlendirme uygulamaları ikinci dünya savaşından sonra hız kazanmış olsa da, ilk olarak 1920'lerde ABD'nde tiyatro, sinema gibi gösteri mekânlarında uygulanmıştır. İlk sistem tasarımları yapıya özel olarak üretilen bileșenlerin, yerinde montaj yapılması ile olmuştur. Fabrika üretimi sistem uygulamaları, paket ünite anlamında 1920'lerin sonlarında gündeme gelmiştir ve bu dönemde soğutucu akışkan olarak, sülfür dioksit, amonyak ve karbondioksit kullanılmıştır.

İkinci Dünya Savaşı'nın son bulması ile birlikte iklimlendirme konusu ve kullanılan sistemler hızlı şekilde gelişmeye başlamıştır. Bu dönemde küçük ölçekli yapılarda hazır paket üniteler kullanılmış, büyük yapılarda ise sıcak veya soğuk suyun akışkan olarak kullanıldığı sistemler oluşturulmuştur. Santrifüj soğutucular (chiller), sıcaklık kontrolü sağlayan (fan-coil) üniteler ve hava tutma üniteleri (air-handling units) üretilmiştir. Bu sistemlere ek olarak indüksiyon sistem, yeniden isitma terminalleri, ikili-kanal sistem (double-duct) ve değişken hava debili sistem (Variable Air Volume, VAV) gibi sistemlerin üretilmesi de bu dönemde olmuștur. Önceleri değişken hava debili sistemlerin yapıda kullanımı çok tercih edilmese de, 1973'deki enerji krizi döneminde verimlerinin yüksek olması sistemin tercih sebebi olmuş ve birçok yapıya uygulanmıștır. Güncel duruma bakıldığında 
çoğunlukla, ısıtma ihtiyacının statik ısıtma yani radyatör ısıtması, soğutma ihtiyacının ise bireysel paket sistemler ile karşılandığı görülebilmektedir. Buna ek olarak büyük yapılarda, merkezi ısıtma (kazanlı sistem) ve merkezi iklimlendirme santralleri (HVAC) kurularak konfor şartları sağlanmaya çalışılmaktadır.

HVAC sistemlerini, günümüzde çalışma ilkelerine göre sınıflandıracak olursak dört başlık altında sıralamak mümkündür.

a. Çok veya Tek Üniteli Bireysel Paket Sistemler (Doğrudan Genleşmeli Sistemler).

$\mathrm{Bu}$ sistemlere örnek olarak, pencere tipi, oda tipi, gizli tavan tipi, kanal tipi, çatı tipi paket klima ve bölünmüş (split) klima sistemlerini sayabiliriz.

b. Havalı Sistemler (All-Air).

Havalı sistemleri kendi içinde, tek kanallı sabit hava debili (CAV- Constant Air Volume), tek kanallı değişken hava debili (VAV- Variable Air Volume) ve çift kanallı tek zonlu veya çok zonlu sistemler olarak sinıflandırabiliriz.

c. Havalı-Sulu Sistemler (Air-Water).

d. Sulu Sistemler (All-Water).

Sulu sistemler iki, üç veya dört borulu sulu sistemler (fan-coil) olarak sayılabilir.

\section{Yapıda HVAC Sistem Seçimi - Hedefler}

Bilinen tüm sistemler ile bütün yapılar soğutulup, ısitılabilirler. Fakat bu noktada yapının nasıl işletildiği önem kazanmaktadır. Yapı işletmesine uyumlu sistem ve sistem bileşenlerinin en doğru olanı seçilmelidir [2]. Sistem seçimi yapılırken öncelikle hangi amaca hizmet edeceği, beklentilerin, hedeflerin neler olduğu tespit edilmelidir. Tablo 1'de, HVAC sistemi seçimi için hedefler ve etkiler/etkenler tablosu oluşturulmuş, tasarımı yapılacak sistem ile sağlanmak istenebilecek hedeflerin ve bu sistemin uygulandığında etkilerinin neler olabileceği verilmiştir.

HVAC sistemlerin hepsi ile her yapı türü iklimlendirilebileceğine göre, bu noktada doğru kararları vermek, uygun yöntemi seçmek ve projelendirmek önem kazanmaktadır. Unutulmamalıdır ki seçilen sistem, yapının cephesine, donatısına, tüm bileşenlerine ve tasarımına etki edebilir. Kullanıcıların konforlu bir yaşam için ihtiyaçları, dolayısı ile bu ihtiyaçlara da cevap verebilmek için yapının gereksinimleri olacaktır. Tablo 1'de, bahsedilen hedeflere ve yapının fonksiyonuna bağlı olarak bunlara ilave düşünülebilecek hedeflere, yapının cevap verebilmesi için, Şekil 4'de verilen gereksinimler dikkatli irdelenmelidir.

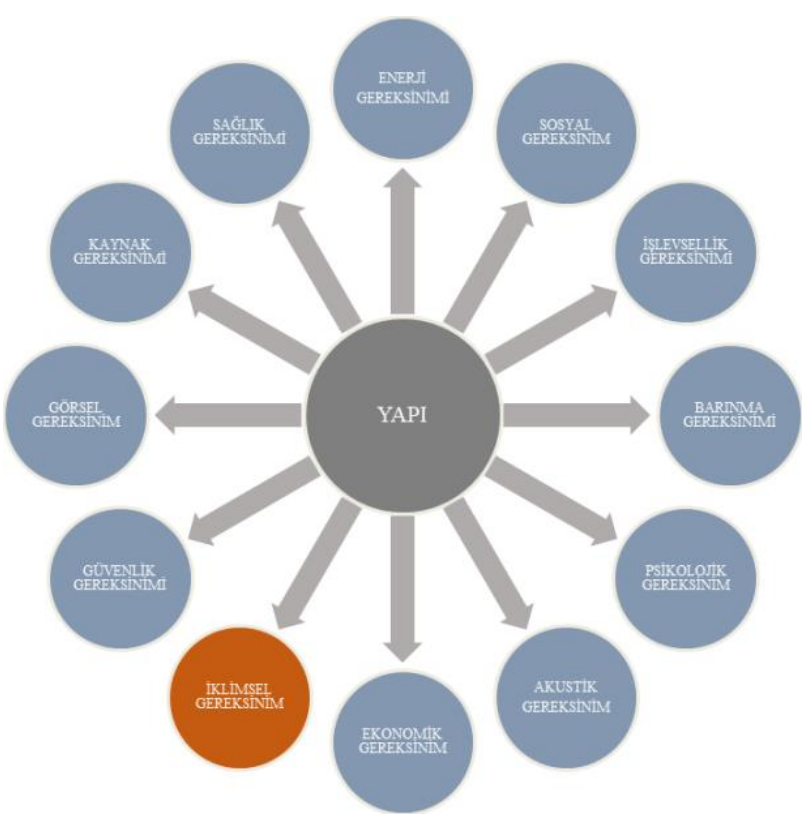

Şekil 4. Konforlu Yașam Alanı: Hedeflerin Belirlenebilmesi İçin Birey Gereksinimleri

Şekil 4'de bahsedilen gereksinimler, konforlu yaşam alanı tarif edilirken asla göz ardı edilemezler. $\mathrm{Bu}$ gereksinimler mimari açıdan yapı tasarımına, sistemlerin seçimi-boyutlandırılması ve entegre edilmesi sırasında değişikliklere sebep olabileceği, mimari konseptin bu durumdan etkilenebileceği düzey önem kazanmaktadır. Mimarlar, ilgili sistemi ve bu sistemin performansını iyi biliyor olmalı, mimari tasarım sırasında söz konusu kriterleri göz önünde bulundurmalıdır. Tesisat mühendisleri, mal sahibi istekleri, çeşitli hesap ve boyutlandırma kuralları, mimarların hayal güçlerini ve mimari tasarımlarını sınırlama eğilimi gösterebilir. Tasarımcının ortaya koymak istediği mimari konsepte ulaşmada, gereksinimler, hedefler, hedeflerin yapı ve tasarım konsepti üzerinde oluşturabileceği muhtemel etkiler, ancak mimarlar ve mühendislerin uyumlu çalışması ile çözüme ulaştırıla bilinir. Tüm bu sistemlerin yapının estetiğine olan etkileri, tesisat mühendisleri tarafından değil mimarlar tarafından düşünülmeli, özellikle seçilen sistemin boyutlandırılması ve uygulanması aşamalarında süreçler mimarlar tarafından takip edilmelidir. $\mathrm{Bu}$ yöntem, muhtemel oluşabilecek olumsuz sürprizleri, süre ve ekonomik kayıpları ortadan kaldırmasının yanı sıra mimari konseptin korunabilmesini de sağlayacaktır.

\section{Yapıda HVAC Sistem Seçimi - Öncelikler}

Herhangi bir HVAC sistem tüm imkanları barındıramayacağından dolayı, soğutma veya ısıtma önceliği başlangıçta belirlenmelidir. Buna örnek verecek olursak, ısıtma ihtiyacı süresi üç ay, soğutma ihtiyacı ise sekiz ay olan bir bölgede teşkil edilecek bir sistemde öncelik soğutma ihtiyacıdır ve ısıtma ihtiyacı ikinci planda kalmaktadır. Bu noktada HVAC sistem seçiminde ve tasarımında soğutma yükleri öncelik kazanmaktadır. Bu tür bir bölgede soğuk hava 
tavan bölgesinden mekâna verilmelidir. Verilecek soğutulmuş hava yoğunluk bakımından yüksek düzeyde olacağından mekân içerisindeki sabit havaya karıșımı kullanıcılar üzerinde hissedilir konfor artıșı sağlayabilecektir. Bununla birlikte ısıtma ihtiyacı süresi yedi ay, soğutma ihtiyacı ise üç ay olan bir bölgede teşkil edilecek bir sistemde öncelik isıtma ihtiyacıdır. Dolayısı ile bu bölge için ısıtma ihtiyacı birinci önceliğe soğutma ihtiyacı ise ikinci önceliğe sahip olmaktadır. Bu tür sistemlerde ısıtma ihtiyacı hacmin alt kotlarından sağlanmalı, özellikle sessiz çalışan cihazlar seçilmelidir. Hacmin pencere açıklıkları altına yerleștirilecek ısıtma ekipmanları doğru bir secim olacaktır. Soğutma süresinin mevsimsel olarak kısa olduğu bu bölgelerde kanallı split sistemlerin kullanılması avantajlı olacaktır. Söz konusu bu soğutma sitemine ilave edilecek olan temiz hava girişi sayesinde mekân basınçlandırılabilecek ve mekâna kirlilik girişinin önüne geçilecektir [3].

Sistemin belirlenmesinde dış hava nem düzeyi göz önünde bulundurulmalıdır. Nem düzeyi düşük bölgelerde kış aylarında nemlendirme imkânı seçilecek sisteme kazandırılmalıdır. Bununla birlikte nem düzeyi yüksek bölgelerde, nem kontrolü sağlayabilmek için, nem toplayıcı cihazlar kullanılması düşünülmelidir. Ofislerde kullanılan elektronik cihazlar, aydınlatma elamanları ve kullanıcılar sebebi ile ısı kazanımı fazla olmaktadır. $\mathrm{Bu}$ açıdan ofislerin, konut mekânlarından farklı olarak soğutma ihtiyacı ve süresi daha fazla olmaktadır. Dolayısı ile uygulama alanına ait özellikler düşünülmesi gereken öncelikler arasına girebilir.

Tablo 1. HVAC Sistemi Seçimi İçin Hedefler ve Etkiler / Etkenler Tablosu

\begin{tabular}{|c|c|c|c|c|c|}
\hline \multicolumn{6}{|c|}{ HVAC SISTEMİ SEÇİMİ İÇİN HEDEFLER VE ETKENLER TABLOSU } \\
\hline \multicolumn{3}{|r|}{ HEDEFLER } & \multicolumn{3}{|r|}{ ETKİLER - ETKENLER } \\
\hline 1. & KONFOR HEDEFI & $\begin{array}{l}\text { Insanlar ancak belirli çevre koşullarında kendilerini rahat } \\
\text { hissederler. Konfor şartları adı verilen bu şartlar HVAC } \\
\text { sayesinde mekanik olarak temin edilebilir. Bunun için } \\
\text { insanların yaşadığı her yerde (konutlar, iş yerleri, alışveriş } \\
\text { merkezleri, kurumlar v.b.) HVAC'ın hedefi konfordur. Pek } \\
\text { çok faktöre bağlı olarak değișken olan konfor şartlarının } \\
\text { sürekli olarak temini kolay değildir ve problem dinamik } \\
\text { olarak ele alınmak zorundadır. }\end{array}$ & 1. & \begin{tabular}{|l|} 
YER IHTIYACI VE \\
CEPHEYE OLAN ETKISI
\end{tabular} & $\begin{array}{l}\text { Yapının dış cephesi seçilen sistem ile değişmekle birlikte HVAC } \\
\text { uygulamalarından çok etkilenir. Örneğin soğutma ve/veya ısıtma } \\
\text { için hava soğutmalı HVAC tercih ediliyorsa, yapı cephesinde dış } \\
\text { ünitelerin görünür halde kalması istenmez. Bu nedenle yapı } \\
\text { içinde dış üniteler için uygun yer ayrılması gerekir. HVAC yapı } \\
\text { içine yerleştiriliyorsa, HVAC'ın havasının dış ortama atılması ve } \\
\text { soğutulması için dış ortam havasının dış ünitelerin bulunduğu } \\
\text { yere kadar alınması gerekir. Bunun için yapı cephesinde belirgin } \\
\text { şekilde panjurlara ihtiyaç duyulur. Eğer HVAC sistem hava } \\
\text { soğutmalı değilse, buna ihtiyaç yoktur. Yapı cephesinde taze } \\
\text { hava ve egzoz havası menfezleri için yer ayrılması gereklidir. } \\
\text { Yapı şaftlarından taze hava ve egzoz havası kanalları } \\
\text { projelendirilerek havalandırma ihtiyacından kaynaklı alan kaybı } \\
\text { engellenebilir. }\end{array}$ \\
\hline 2. & PROSES HEDEFI & $\begin{array}{l}\text { Endüstride HVAC genellikle proses gereksinimi nedeniyle } \\
\text { yapılır. Bu tür, hedefi proses olan, HVAC uygulamalarından } \\
\text { en bilinenlerden biri, temiz oda tekniğidir. Ilaç üretimi, } \\
\text { elektronik endüstrisi gibi alanlarda, üretim hollerinde } \\
\text { mikrop, toz v.b. havada asılı tanecik sayısı belirli sınır } \\
\text { değerlerin üzerine çıkmamalıdır. Burada HVAC'ın amacı bu } \\
\text { filtrasyonun sağlanmasıdır. Tekstil endüstrisinde hedef } \\
\text { belirli bağılı nem değerlerinin sabit tutulması veya bazı } \\
\text { durumlarda sıcaklığın da kontrol edilmesidir. Bu örneklere } \\
\text { ek olarak gıda ve kimya endüstrisinden farklı gereksinimler } \\
\text { sayılabilir. }\end{array}$ & 2. & $\begin{array}{l}\text { ÇEVRE ZON VE } \\
\text { ÇEKIRDEK ZON } \\
\text { FAKTÖRÜ ETKISİ }\end{array}$ & $\begin{array}{l}\text { Çok katlı yapılar, yüksekliğinin zeminde kapladığı alanına oranı } \\
\text { oldukça büyük olabilecek șekilde tasarlanabilen yapılardır. Bu } \\
\text { tür yapılarda radyasyonla ısı kazancı gün içinde farklı } \\
\text { cephelerde büyük farklııklar gösterir. Çevre zonda güneșin, dış } \\
\text { hava sıcaklığının, rüzgarın etkisiyle sürekli değişen bir ısı yükü } \\
\text { varken, çekirdek zonda ise yükler değişik saatlerde farklılık } \\
\text { göstermez ve sabittir. Genelde çekirdek zonda elektrikli cihazlar, } \\
\text { aydınlatma, insan faktörü sebebiyle yaz-kıs sabit bir } \\
\text { iklimlendirme ihtiyacı vardır. Yapıda bu bölgeler genellikle wc- } \\
\text { banyo, tesisat şaftı, servis hacimleri v.b. alanlardan oluşur. }\end{array}$ \\
\hline 3. & KORUMA HEDEFI & $\begin{array}{l}\text { Depo yapılarında gıda korunmasında, müzelerde değerli } \\
\text { koleksiyonların saklanmasında, askeri alanlarda askeri } \\
\text { malzemelerin korunmasında, tarihi yapıların korunması ve } \\
\text { ortam havasının belirli şartlarda tutulmasında, özellikle } \\
\text { nemin kontrol edilmesinde HVAC sistemler kullanılır. }\end{array}$ & 3. & $\begin{array}{l}\text { RÜZGAR HIZI VE } \\
\text { BASINÇ, ETKISI }\end{array}$ & $\begin{array}{l}\text { Yapılarda rüzgar hızı önemli bir faktördür. Üst katlara çıkıldıkça } \\
\text { rüzgar hızı artar. Rüzgar hızına bağıı olarak yapının rüzgar } \\
\text { yönündeki cephesinde pozitif basınç meydana gelirken, ters } \\
\text { yönde negatif basınç oluşur. Yapı cephesindeki açıklıklardan } \\
\text { rüzgar hızına bağlı olarak sızan hava miktarı oldukca fazladır. } \\
\text { Isınan havanın yükselip soğuk havanın çöktüğünü göz önünde } \\
\text { bulundurursak üst katlardaki sistem tasarımının bu doğrultuda } \\
\text { düşünülmesi gereklidir. Öte yandan hem yangın güvenliği } \\
\text { açısından hem de rüzgarın yapı cephesindeki etkilerinden dolayı } \\
\text { oluşabilecek by-pass riskinin engellenmesi amacı ile egzoz } \\
\text { havası atışları ve taze hava alış menfezleri yapının farklı } \\
\text { cephelerinde olmalıdır. }\end{array}$ \\
\hline 4. & ÜRETKENLIK HEDEFI & $\begin{array}{l}\text { Çalışma ortamının konfor şartlarından uzak olması, } \\
\text { çalışanların performansını düşürür. HVAC uygulamalarında } \\
\text { bir diğer hedef çalışanların performansının ve üretkenliğinin } \\
\text { artırılmasıdır. }\end{array}$ & 4. & $\begin{array}{l}\text { İKLIMSEL VERÍLER } \\
\text { ETKISI }\end{array}$ & $\begin{array}{l}\text { Yapıda HVAC sistem seçimi yapılırken iklimsel verilerin } \\
\text { düšunülmesi ve ona göre bir tercih yapılması gereklidir. } \\
\text { Ülkemizde iklim farklılıkları sebebiyle farklı uygulamalar } \\
\text { yapılabilir. İklimsel konforun ve üretkenlik hedefinin } \\
\text { sağlanmasında çoğrafi ve iklimsel veriler etkili olabilmektedir. }\end{array}$ \\
\hline 5. & $\begin{array}{l}\text { MÜLK DEĞERININ } \\
\text { ARTTIRILMASI HEDEFI }\end{array}$ & $\begin{array}{l}\text { HVAC uygulamasının bir başka hedefi ise mülkün değeriyle } \\
\text { ilgilidir. Mal sahibi mülkünün kıymetini artırmak ve daha } \\
\text { yüksek bir fiyatla satabilmek veya kiraya verebilmek üzere } \\
\text { HVAC sistemi kurdurmak isteyebilir. Bu hedeflerden her } \\
\text { birinde seçilecek HVAC sisteminin aranan özellikleri } \\
\text { ekonomik gerekceler ile farklılık gösterebilir. }\end{array}$ & & $\begin{array}{l}\text { ENERJI EKONOMISI } \\
\text { ETKISI }\end{array}$ & $\begin{array}{l}\text { Tüm bu faktörler gözönüne alındığında tasarımcı sistem } \\
\text { işletilmesi esnasında enerji kaybının minimum seviyelerde } \\
\text { tutulabilmesini, sistemin yatırımcıları tarafindan öngörülen } \\
\text { kurulum ve işletim maliyetlerinin kabul edilebilir ölçülerde } \\
\text { olmasını sağlayabilmelidir. }\end{array}$ \\
\hline
\end{tabular}


Tablo 2. HVAC Sistemlerin Karșılaștırma Tablosu

\begin{tabular}{|c|c|c|c|c|c|c|c|c|c|c|c|c|c|c|c|c|c|c|c|c|c|c|c|c|}
\hline & & & & & & HVA & $\mathrm{AC} \mathbf{s} \mathbf{i}$ & ISTE & EMLE & zín 1 & KAR & ŞILA & ȘTI & RMA & TABI & LOS & & & & & & & & \\
\hline & & PERFORM & ZMANS & & $\begin{array}{l}\text { ISLLETM } \\
\text { MALIYYE }\end{array}$ & & & $\begin{array}{l}\text { TEM iI } \\
\text { MAL }\end{array}$ & $\begin{array}{l}\text { LK YAT } \\
\text { LiYETT }\end{array}$ & & & $\begin{array}{l}\text { IS-BSAK } \\
\text { ARIM } \\
\text { LLETME }\end{array}$ & & & Mim & AARI & & & & $\begin{array}{l}\text { ANLAMA } \\
\text { MONTAJ }\end{array}$ & & DiĞER & & \\
\hline & 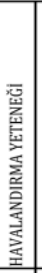 & 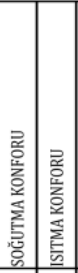 & 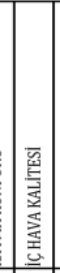 & 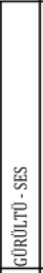 & 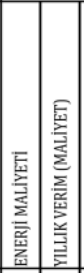 & 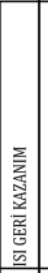 & 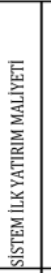 & $\begin{array}{l}\text { 善 } \\
\text { 产 } \\
\text { 产 } \\
\text { 兽 } \\
\end{array}$ & 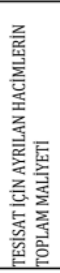 & 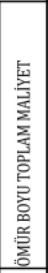 & 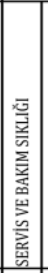 & 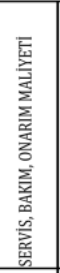 & 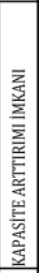 & 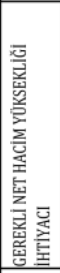 & 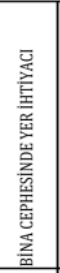 & 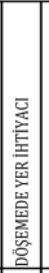 & 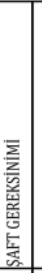 & 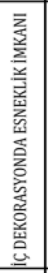 & 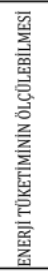 & 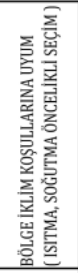 & 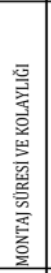 & 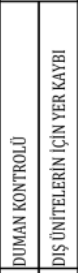 & 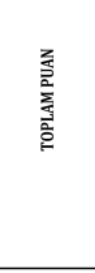 & 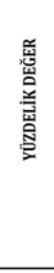 \\
\hline & 1 & \begin{tabular}{|l|l|}
3 & 4 \\
\end{tabular} & 2 & 2 & \begin{tabular}{|l|l|}
2 & 1 \\
\end{tabular} & 0 & 5 & 4 & 5 & 5 & 5 & 5 & 5 & 4 & 2 & 3 & 5 & 5 & 5 & 2 & 5 & \begin{tabular}{|l|l|}
0 & 2 \\
\end{tabular} & 82 & \\
\hline & & $12 / 2 !$ & & & $1 / 5$ & & & & $9 / 20$ & & & $15 / 15$ & & & 19 & $/ 25$ & & & & $12 / 15$ & & $2 / 10$ & $82 / 125$ & $05 \%$ \\
\hline & 3 & \begin{tabular}{|l|l|}
4 & 3 \\
\end{tabular} & 3 & 3 & \begin{tabular}{|l|l|}
3 & 5 \\
\end{tabular} & 4 & 3 & 5 & 5 & 4 & 3 & 3 & 5 & 4 & 4 & 3 & 4 & 5 & 5 & 3 & 5 & \begin{tabular}{|l|l|}
0 & 3 \\
\end{tabular} & 92 & \\
\hline SisTEMi & & $16 / 25$ & & & $12 / 15$ & & & & $7 / 20$ & & & $11 / 15$ & & & 20 & $/ 25$ & & & & $13 / 15$ & & $3 / 10$ & $92 / 125$ & $73 \%$ \\
\hline & 4 & \begin{tabular}{|l|l|}
5 & 4 \\
\end{tabular} & 3 & 4 & \begin{tabular}{|l|l|}
3 & 3 \\
\end{tabular} & 5 & 4 & 5 & 3 & 4 & 5 & 5 & 5 & 4 & 3 & 4 & 4 & 5 & 5 & 5 & 5 & \begin{tabular}{|l|l|}
5 & 3 \\
\end{tabular} & 105 & \\
\hline zoz & & $20 / 25$ & & & $11 / 15$ & & & & $6 / 20$ & & & $15 / 15$ & & & 20 & $/ 25$ & & & & $15 / 15$ & & $8 / 10$ & $105 / 125$ & \\
\hline & 2 & \begin{tabular}{l|l|}
4 & 3 \\
\end{tabular} & 2 & 3 & \begin{tabular}{|l|l|}
3 & 3 \\
\end{tabular} & 5 & 3 & 5 & 3 & 4 & 2 & 3 & 5 & 4 & 5 & 3 & 4 & 5 & o & 3 & 3 & \begin{tabular}{|l|l|}
5 & 4 \\
\end{tabular} & 86 & \\
\hline EGZO & & $14 / 25$ & & & $11 / 15$ & & & & $5 / 20$ & & & $10 / 15$ & & & 21 & $/ 25$ & & & & $6 / 15$ & & $9 / 10$ & $86 / 125$ & $68 \%$ \\
\hline & 5 & \begin{tabular}{|l|l|}
5 & 5 \\
\end{tabular} & 5 & 5 & \begin{tabular}{|l|l|}
5 & 5 \\
\end{tabular} & 5 & 2 & 5 & 1 & 3 & 2 & 3 & 5 & 3 & 5 & 2 & 1 & 5 & 0 & 5 & 3 & \begin{tabular}{|l|l|}
5 & 3 \\
\end{tabular} & 93 & \\
\hline VAV + RADYATÖR ISITMASI & & $25 / 25$ & & & $15 / 15$ & & & & $1 / 20$ & & & $10 / 15$ & & & 16 & $/ 25$ & & & & $8 / 15$ & & $8 / 10$ & $93 / 125$ & $74 \%$ \\
\hline & 4 & \begin{tabular}{|l|l|}
5 & 1 \\
\end{tabular} & 4 & 2 & \begin{tabular}{|l|l|}
1 & 1 \\
\end{tabular} & 5 & 1 & 5 & 1 & 2 & 2 & 3 & 5 & 2 & 5 & 2 & 2 & 5 & 0 & 3 & 3 & \begin{tabular}{|l|l|}
5 & 3 \\
\end{tabular} & 72 & \\
\hline SISTEM + EGZOZ SISTEMI & & $16 / 25$ & & & $7 / 15$ & & & & / 20 & & & $10 / 15$ & & & 16 & $/ 25$ & & & & $6 / 15$ & & $8 / 10$ & $72 / 125$ & $57 \%$ \\
\hline & 2 & \begin{tabular}{|l|l|}
4 & 4 \\
\end{tabular} & 3 & 4 & \begin{tabular}{|l|l|}
5 & 5 \\
\end{tabular} & 4 & 3 & 5 & 5 & 4 & 2 & 3 & 5 & 4 & 5 & \begin{tabular}{|l|}
3 \\
\end{tabular} & 4 & 5 & 5 & 4 & 3 & \begin{tabular}{|l|l|}
5 & 4 \\
\end{tabular} & 100 & \\
\hline $\begin{array}{l}\text { SSISTTM + T TZEE HAVA VE } \\
\text { EGZOZ SISTEMi }\end{array}$ & & $17 / 25$ & & & $14 / 15$ & & & & 7/20 & & & $10 / 15$ & & & 211 & $/ 25$ & & & & $12 / 15$ & & $9 / 10$ & $100 / 125$ & $80 \%$ \\
\hline
\end{tabular}

HVAC sistemin ölçüleri ve boyutu mimari tasarım ile uyumlu olmalıdır. Mimarların tasarım istekleri ile HAVC imkânları, belirlenecek olan hava menfezleri v.b. ekipmanları belirlemektedir. Bu durumda bir diğer öncelik gürültü kontrolü olmaktadır [2]. Elde edilmek istenen mimari sınırlamalar ve gürültü kontrolü önceliği başlıca kriter olabilmektedir. Şekil 5'de bir HVAC sistemin yapının çatısında bulunma durumu verilmiştir, bu boyutta bir sistem şüphesiz mimari konsepti ve sinırlamaları etkileyebilecektir. Önceliklere göre en uygun sistemin belirlenmesi daha sağlıklı sonuçların alınabilmesini sağlayacaktır. Seçilmesi düşünülebilecek sistemlerin birbirlerine göre avantaj ve dezavantajları sınıflandırılmalıdır, mimarlar ve tasarımcilar bu sinıflandırma verileri ışığında sistem seçimini sağlıklı yapabileceklerdir.

\section{HVAC Sistemlerin Karşılaştırılması}

Günümüzde yapıda yaygın olarak kullanılan yedi sistem seçilmiş ve karşılaştırılmıştır. $\mathrm{Bu}$ sayede amaca en uygun sistemin belirlenebilmesi ve değerlendirilebilmesi istenmiştir. Unutulmamalıdır ki hiçbir HVAC sistem avantajların tamamını bünyesinde barındıramayacaktır. Fakat her sistemin ideal olarak kullanılabileceği yapılar ve koşullar mevcuttur.

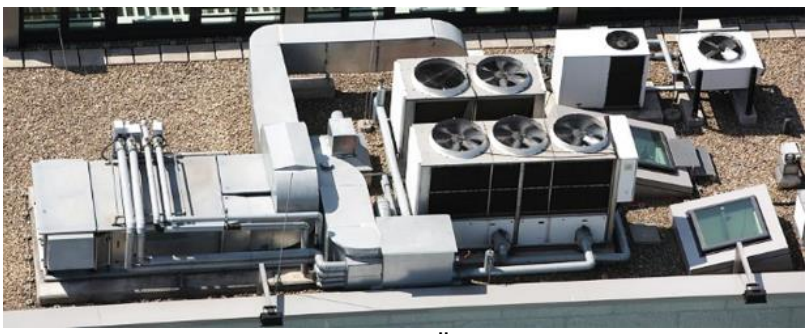

Şekil 5. Bir HVAC Sistemi Dış Ünitesi ve Çatıda Bulunma Durumu.

Tablo 2'de seçilen yedi HVAC sistem, performans, işletme maliyetleri, sistem ilk yatırım maliyetleri, servis-bakım-onarım ve işletme giderleri, mimariye olan etkileri, planlama ve montaj kolaylıklarına göre sinıflandırılarak, avantajları ve dezavantajları 1 ile 5 arasında puanlandırılmıştır. Puanlamada, 5 puan: en iyi durumu veya en düşük maliyeti, 4 puan: iyi durumu veya düşük maliyeti, 3 puan: orta düzeyi veya orta düzeyde maliyeti, 2 puan: kötü durumu 
veya yüksek maliyeti, 1 puan: en kötü durumu veya en yüksek maliyeti ifade etmekte olup, sistemler öncelikle alabilecekleri en yüksek toplam puan üzerinden değerlendirilmiștir. Elde edilen toplam puan yüzdelik değere çevrilerek karşılaştırmada kolaylık sağlanmak istenmiştir. Bu sayede mimarlar ve tasarımcılar için bir referans oluşturulmuştur. Tablo 2'de her sistemde bulunan avantaj ve dezavantajlar ortaya konmuş, kullanıcı ve tasarımcının önceliklerini, sistemlerin özellikleri ile kolaylıkla örtüştürebilmesi sağlanmak istenmiştir.

\section{Tartışma ve Sonuç}

İklimsel konfor şartları mekâna ait hava, hava hareketi, ısı ve nem gibi etkileşim halinde bulunan unsurların belli düzeylerde tutulması ve kontrol edilmesi ile sağlanabilir. Kullanıcı ve mekân arasındaki ısı kayıp ve kazanımı kullanıcı sağlığını olumsuz etkileyecek düzeylerde olmamalıdır. Yapı içerisinde isıl konforu sağlamak ve koruyabilmek amaçlanıyor ise mutlaka çevresel ve mevsimsel şartlar incelenmelidir. Yapıya ait işlevler ve kullanıcı senaryoları dikkate alınmalı iklimsel konfor hedefleri doğru belirlenmeli, bu hedeflere ulaşılmakta kullanılması düşünülen muhtemel yöntemlerin yapı üzerindeki etkileri irdelenmelidir.

Gün geçtikçe kullanıcı gereksinimleri, kalite düzeyi ve talebi artmaktadır. Ortamdaki hava kalitesinin bozulması, kullanıcılarda bulundukları ortamdan uzaklaşma isteği doğurmaktadır. Yapıda herhangi bir şartlandırmaya ihtiyaç duyulmadan hava hareketini doğal havalandırma ile sağlamak elbette mümkündür. Ancak günümüzde bunu her yapı türü için söyleyebilmek maalesef mümkün değildir. Yapıyı mekanik olarak iklimlendirmeye imkân veren HVAC sistemler ise tasarımcılara, oldukça fazla seçenek sunmakta, doğru tasarım ve uygulamalar yapılabilmesi durumunda, büyük kolaylıkları ve konforu beraberinde getirmektedirler.

HVAC sistemler ile birçok yöntem ve teknoloji birlikte veya ayrı ayrı kullanılabilmekte, iklimsel konfor açısından mükemmel fizik çevreler oluşturulabilmektedir. HVAC sistemler kullanılmaya başlandıkları günden bu yana değişim ve gelişim göstermiştir. Her yapı türünü, teorik olarak tüm HVAC sistem çeşitleri ile iklimlendirmek mümkündür. Fakat tüm teknolojik bileșenler gibi bu sistemlerde, ilk yatırım ve işletme maliyetlerine sahiptirler. Enerjiye ihtiyaç duyar, kaynak kullanırlar ve hizmet sağlayabilecekleri performans düzeyleri bellidir. Sistem seçiminde bu başlıklar dikkatli incelenmeli, hesaplamalar titizlikle yapılmalıdır. Tasarımcilar tarafından sistemler, avantaj ve dezavantajları bakımından mutlaka karşılaştırılmalı, yapıya en uygun sistem veya birlikte kullanılabilecek sistem birleşimleri seçilmelidir. Yapıya ait mimari tasarımın muhtemel olumsuz etkilenebilme durumu, seçilen sistemin veya sistemlerin doğru planlanması ve uygun montajının sağlanması ile mutlaka önlenmelidir.

\section{Kaynakça}

[1] Öztürk, H.,K., Atalay, Ö., Yllancı, A., 2005. Yapılarda Kullanılan HVAC Sistemlerinde Kontrol Ve Enerji Verimliliği, Tesisat Mühendisleri Dergisi, Sayı: 90, S: 69.

[2] Küçükçalı, R., 2007. Çok Katlı Yüksek Konutlarda Hvac Sistemleri Seçimi, Türk Tesisat Mühendisleri Dergisi, Sayı 50, S: 22.

[3] Ashrae, 2010. Ashrae Standard 55-2010, Thermal Environmental Conditions For Human Occupancy, American Society of Heating, Refrigerating And Air-Conditioning Engineers, Inc., Atlanta.

[4] Anonim, 2007., Yüksek Yapılarda Tesisat, Isısan Yayınları, İstanbul.

[5] Ashrae, 1989. Ashrae Handbook of Fundamentals, American Society Of Heating, Refrigerating And Air-Conditioning Engineers, Inc., Atlanta.

[6] Ashrae, 1997. Ahsrae Temel El Kitabı (Fundamentals), Çev. T. Derbentli, Tesisat Mühendisleri Derneği Teknik Yayınlar 2, İstanbul.

[7] Fanger, P.O., 1972. Termal Comfort, Mc Graw Hill, New York.

[8] Schramek, E.R., 1996. Recknagel-Sprenger Schramek- Isıtma Ve Klima Tekniği El Kitabı, Çev. O. Saraçoğlu, A. Razgat, Tesisat Mühendisleri Derneği Teknik Yayınlar, İstanbul.

[9] Anonim, 2017. Güneş Enerjisinden Elektrik Üretiminde Mevcut Durum, İmkanlar, Sorunlar Ve Çözüm Önerileri. http://www.arsiv.mmo.org.tr/pdf/12060.pdf (Erişim Tarihi: 25.10.2018).

[10] Anonim, 2016. Yapilarda Kullanilan HVACSistemlerinde Kontrol ve Enerji Verimliligi. https://www.termodinamik.info/bilimsel/yapil arda-kullanilan-hvac-sistemlerinde-kontrol-veenerji-verimliligi (Erişim Tarihi: 23.09.2018).

[11] Anonim, 2008. Sistem Seçimi, Yakıt Ekonomisi ve Isl Konfor - 1. http://www.tesisatmarket.com/teknik/sistemsecimi $\neg y a k i t \neg$ ekonomisi $\neg$ ve $\neg$ isil $\neg$ konfor $\neg 1$ (Erişim Tarihi: 15.10.2018). 